\title{
Erratum
}

\section{A report of Streptococcus pneumoniae serotype 6D in Europe}

M. H. Nahm, M. B. Oliver, L. Siira, T. Kaijalainen, L. M. Lambertsen and A. Virolainen

Journal of Medical Microbiology (2011), 60, part 1, 46-48. doi:10.1099/jmm.0.48729-0

The following text should have been included at the end of the acknowledgements on page 47. The University of Alabama at Birmingham owns the intellectual property rights to the $6 \mathrm{C}$ and $6 \mathrm{D}$ serotypes described in this work. M. H. N. and M. B. O. are employees of the University of Alabama at Birmingham. 